\title{
On the potential contribution of open lead particle emissions to the central Arctic aerosol concentration
}

\author{
A. Held ${ }^{1,2}$, I. M. Brooks ${ }^{3}$, C. Leck ${ }^{2,4}$, and M. Tjernström ${ }^{2,4}$ \\ ${ }^{1}$ University of Bayreuth, Bayreuth Center of Ecology and Environmental Research, 95440 Bayreuth, Germany \\ ${ }^{2}$ Stockholm University, Department of Meteorology, 10691 Stockholm, Sweden \\ ${ }^{3}$ University of Leeds, School of Earth and Environment, Leeds, LS2 9JT, UK \\ ${ }^{4}$ Bert Bolin Center for Climate Research, Stockholm University, 10691 Stockholm, Sweden
}

Received: 10 September 2010 - Published in Atmos. Chem. Phys. Discuss.: 25 October 2010

Revised: 13 March 2011 - Accepted: 20 March 2011 - Published: 1 April 2011

\begin{abstract}
We present direct eddy covariance measurements of aerosol number fluxes, dominated by sub- $50 \mathrm{~nm}$ particles, at the edge of an ice floe drifting in the central Arctic Ocean. The measurements were made during the ice-breaker borne ASCOS (Arctic Summer Cloud Ocean Study) expedition in August 2008 between $2^{\circ}-10^{\circ} \mathrm{W}$ longitude and $87^{\circ}-87.5^{\circ} \mathrm{N}$ latitude. The median aerosol transfer velocities over different surface types (open water leads, ice ridges, snow and ice surfaces) ranged from 0.27 to $0.68 \mathrm{~mm} \mathrm{~s}^{-1}$ during depositiondominated episodes. Emission periods were observed more frequently over the open lead, while the snow behaved primarily as a deposition surface. Directly measured aerosol fluxes were compared with particle deposition parameterizations in order to estimate the emission flux from the observed net aerosol flux. Finally, the contribution of the open lead particle source to atmospheric variations in particle number concentration was evaluated and compared with the observed temporal evolution of particle number. The direct emission of aerosol particles from the open lead can explain only 5$10 \%$ of the observed particle number variation in the mixing layer close to the surface.
\end{abstract}

\section{Introduction}

The Arctic region north of $80^{\circ} \mathrm{N}$ provides a unique setting to investigate the impact of aerosol particles on the climate system. Complex aerosol-cloud-ice-ocean interactions can be studied under very limited anthropogenic influence especially during the summer months (Leck and Persson, 1996).

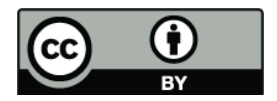

Correspondence to: A. Held (andreas.held@uni-bayreuth.de)
Minimum effects from continental sources are encountered from June to August. At this time, the central Arctic lower atmosphere is effectively isolated from anthropogenic emissions due to the prevailing atmospheric circulation patterns and near-surface processes in the marginal ice zone. However, during the Arctic haze period in winter and early spring the influx of polluted mid-latitude air and extended aerosol residence times can lead to elevated aerosol concentrations (Heintzenberg and Leck, 1994).

The complex aerosol-cloud-radiation interactions in the Arctic constitute a warming factor for the regional climate during most of the year (e.g. Intrieri et al., 2002; Tjernström, 2005). This is due partly to the semi permanent ice cover, raising the surface albedo compared to that of the ocean surface. In addition, the cloud albedo is reduced due to the very clean air. Under clean air conditions as observed in the Arctic summer, even small numbers of ice nuclei (Bigg, 1996) can potentially play a key role in cloud development, and thus the regional climate (e.g. Prenni et al., 2007; Möhler et al., 2007). As long as there are no major intrusions of polluted air (e.g. Carrio et al., 2005), aerosol particle and cloud condensation nuclei $(\mathrm{CCN})$ concentrations in the high Arctic are extremely low (e.g. Bigg et al., 1996; Bigg and Leck, 2001; Leck et al., 2002; Lohmann and Leck, 2005). This will result in low concentrations of relatively large cloud droplets, leading to a relatively low cloud albedo and to frequent formation of drizzle (e.g. Rasmussen et al., 2002). Previous studies indicate that drizzle formation is likely to affect boundary layer motions on a variety of temporal scales (e.g. Feingold et al., 1999).

Optically thin stratiform clouds play a prominent role over the central Arctic Ocean. While they are the single most important factor determining the surface radiation budget,

Published by Copernicus Publications on behalf of the European Geosciences Union. 
current climate models are unable to yield a realistic description of Arctic clouds and their impact on the surface radiation (e.g. Walsh et al., 2002; Tjernström et al. 2008; Karlsson and Svensson, 2011). In particular, they are far from incorporating the relevant cloud-ice-ocean feedbacks.

Model projections suggest that the Arctic regional climate could transition into a new stable regime with no summer sea-ice within only a few decades (Lenton et al, 2008). This would impact considerably on the Arctic Ocean ecosystem and affect large-scale atmospheric and oceanic circulation patterns. Refined parameterizations of aerosol-cloud feedbacks in global and regional climate models require the development of novel observational capabilities and extensive field investigations. Only then, aerosol sources, sinks, and transport and transformation processes can be identified and quantified.

The cloud albedo has been shown to be very sensitive to particle concentration changes under clean conditions, and for optically thin clouds (Twomey, 1974). In a changing climate, a small increase in CCN could increase the albedo of the clouds and lead to decreased ice melt. In contrast, an increase in ice melt would lead to a decreased surface albedo through formation of melt ponds on the ice (Leck et al., 2004). Over the central Arctic Ocean, a local biogenic source of aerosol particles from bursting bubbles at the water-air interface has been suggested (e.g. Leck and Bigg, 1999, 2005a; Leck et al., 2002). It links marine biological activity, clouds and climate through the ejection of organic microcolloids (Wells and Goldberg, 1991) from the surface microlayer of open leads (Bigg et al., 2004) into the atmosphere. Once airborne, some of these particles may act directly as $\mathrm{CCN}$, while others are activated after condensational growth (Leck and Bigg, 2005b). Even though this source of CCN may explain some important aspects of the Arctic aerosol-cloud-climate relationship, many of the controlling mechanisms remain unknown. One example is the dependence of the bubble-bursting mechanism on wind, temperature, salinity, and possibly other factors.

This study aims (1) to evaluate the relevance of particles emitted directly from open leads in Arctic aerosol-ice-cloud interactions, and (2) to quantify their contribution to the atmospheric aerosol burden by direct measurements of the net particle flux.

Open leads have been described as potential sources of atmospheric particles for the first time by Scott and Levin (1972). Also, turbulent particle fluxes have been measured previously by eddy covariance in the high Arctic over the open sea and over the pack ice (Nilsson and Rannik, 2001). However, the measurement footprints over the pack ice were generally large, and Nilsson and Rannik (2001) acknowledge that most measurements were influenced by a mix of open lead and ice surfaces. In this study, turbulence measurements were performed closer to the surface and close to the edge of a lead. Thus, the footprint areas are reduced, and a separation of measurements influenced by the open lead and by the ice and snow surfaces is facilitated.

Still, the problem remains that eddy covariance flux measurements yield a net flux which is a superposition of particle emission and deposition fluxes. In order to derive the emission flux, an independent estimate of the deposition flux is required. This estimate may be obtained from a theoretical parameterization of particle deposition; however, a thorough evaluation of the uncertainties introduced is necessary before any further conclusions can be drawn.

\section{Method and site}

Turbulent aerosol number fluxes were measured from an ice floe drifting in the central Arctic Ocean between $2^{\circ}-10^{\circ} \mathrm{W}$ and $87^{\circ}-87.5^{\circ} \mathrm{N}$ from 17 August to 1 September 2008. An eddy covariance system was set up on the edge of an open lead at $2.5 \mathrm{~m}$ above the surface. Depending on the wind direction, the measured turbulent fluxes were influenced by the open lead or by the ice floe. The system consisted of a Gill R3 sonic anemometer (Gill, Lymington, UK) for threedimensional wind measurements, a Licor LI-7500 gas analyzer (Licor, Lincoln, NE, USA) for carbon dioxide $\left(\mathrm{CO}_{2}\right)$ and water $\left(\mathrm{H}_{2} \mathrm{O}\right)$ vapor concentration measurements, and a condensation particle counter CPC 3760A (TSI, St. Paul, MN, USA) for number concentration measurements of particles in a diameter range from $11 \mathrm{~nm}$ to $3 \mu \mathrm{m}$. Even though the CPC detects particles in a wide size range, measurements of the mean aerosol size spectra made during ASCOS and in earlier studies (Covert et al., 1996; Leck and Bigg, 2005a) suggest that the total number concentration, and thus the aerosol number flux, is dominated by sub- $50 \mathrm{~nm}$ particles. The response time of the particle counter, including the sampling line, was approximately $1.4 \mathrm{~s}$. Wind and $\mathrm{CO}_{2} / \mathrm{H}_{2} \mathrm{O}$ data were logged at $20 \mathrm{~Hz}$, and particle number concentration data at $10 \mathrm{~Hz}$, using a MOXA UC7420 computer (Moxa Inc., Brea, CA, USA). All instruments were battery-operated during the entire measuring period.

Aerosol number fluxes were calculated according to standard eddy covariance procedures, with $30 \mathrm{~min}$ averaging, after a coordinate rotation using the planar fit method (Wilczak et al., 2001), and linear detrending of the aerosol number time series. To account for the traveling time of the aerosol sample from the sampling point through the inlet tubing to the particle counter, and the traveling time within the particle counter, a constant time lag of $2.6 \mathrm{~s}$ was used to synchronize the wind with the aerosol time series. This time lag was confirmed by adjusting the sample offset to maximize the covariance given by the cross-correlation function of the vertical wind speed and particle number concentration. The passage through the sampling line also degraded the response time of the system with regard to ambient aerosol concentration changes. 
It is important to bear in mind that this eddy covariance setup with a response time of $1.4 \mathrm{~s}$ cannot resolve $10 \mathrm{~Hz}$ aerosol number concentration fluctuations. The underestimation of the aerosol fluxes due to fluctuation dampening was corrected following Horst (1997). With typical wind speeds of less than $3 \mathrm{~m} \mathrm{~s}^{-1}$, we found the magnitude of this correction to be typically less than $50 \%$.

If turbulent fluctuations of the particle number are small compared to the mean particle number concentration, the Webb correction should be applied to account for the density effect due to heat and water vapor fluxes (Webb et al., 1980). We analyzed the magnitude of the Webb correction for a subset of our data and found a median correction of $2.5 \%$ of the observed aerosol number flux. Because of problems with the turbulent temperature and humidity measurements from which the Webb correction is determined, it is not possible to apply it to the entire aerosol flux data set. Thus, we neglected the small Webb correction for the sake of greater data coverage. No additional corrections were applied to the aerosol fluxes.

Data quality was evaluated by testing the stationarity of the time series following Foken and Wichura (1996). Data were discarded when the average of six 5 min intervals of the standard deviation of the particle number concentration (or temperature) deviated by more than $70 \%$ from the $30 \mathrm{~min}$ standard deviation. We also discarded data if the $30 \mathrm{~min}$ standard deviation of the particle number concentration was larger than $30 \mathrm{~cm}^{-3}$, indicating particle pollution from, for example, snow mobiles or helicopter flights.

Moreover, the integral turbulence characteristic of the vertical wind was calculated as the ratio of the standard deviation of the vertical wind speed, $\sigma_{w}$, and the friction velocity, $u_{*}$, and compared to the parameterization recommended by Thomas and Foken (2002). The calculated $\sigma_{w} / u_{*}$ values deviated less than $30 \%$ from the parameterization when the friction velocity was larger than $u_{*}=0.1 \mathrm{~m} \mathrm{~s}^{-1}$.

Spectral analysis of the aerosol number concentration time series confirmed the limited response time of the eddy covariance setup. Figure 1 presents normalized ogive functions, i.e. cumulative cospectra of the vertical wind speed $w$ vs. sonic temperature $T$ and aerosol number $c$, during two different measurement periods on 20 August and 24 August 2008. On 20 August, shown in Fig. 1a, the contributions to the aerosol cospectrum at frequencies above $0.2 \mathrm{~Hz}$ are negligible. In contrast, on 24 August shown in Fig. 1b, we observe high frequency flux contributions even beyond the frequency corresponding with the approximate response time of the particle counter ( $1.4 \mathrm{~s}$, dashed vertical line). The buoyancy flux ogives exhibit a characteristic shape with flux contributions in the frequency range from $0.01 \mathrm{~Hz}$ to $5 \mathrm{~Hz}$. Since the ogives do not quite flatten out at the highest frequencies, some of the smallest flux-contributing scales are not resolved, but the loss seems to be negligible.
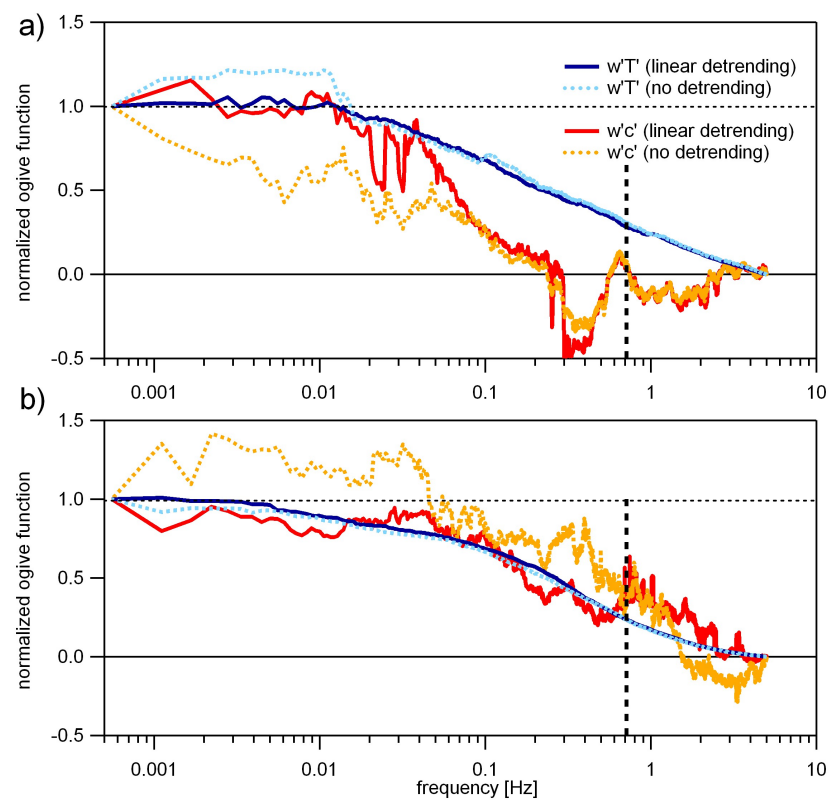

Fig. 1. Normalized ogive functions of vertical wind vs. sonic temperature $\left(w^{\prime} T^{\prime}\right.$, blue) and vertical wind vs. aerosol number concentration $\left(w^{\prime} c^{\prime}\right.$, red). (a) Median ogives from 20 August, 01:0004:00. (b) Median ogives from 24 August, 03:30-07:30. Broken lines in light colors show ogives without linear detrending. Vertical dashed lines indicate the frequency corresponding to the CPC response time.

In general, the aerosol ogives show much higher variability. We attribute some of this variability to changing footprints when small changes in wind speed and direction result in quite different fetches. Some individual aerosol ogives deviate considerably from the expected shape, in particular when data quality is evaluated as poor and the measurements are discarded. Median aerosol ogives as presented in Fig. 1 tend to smooth out some of the variability. On 24 August, the shape of the aerosol and temperature ogives is rather similar. At low frequencies, the buoyancy flux ogives flatten out around $0.005 \mathrm{~Hz}$, whereas the aerosol ogives without detrending deviate from this behavior. Thus, in addition to high frequency flux dampening and variability in all frequencies due to spatial heterogeneity, low frequency contributions due to long-term trends were found, yet removed by linear detrending.

The surface roughness was characterized by an estimate of the roughness length $z_{0}$ which was derived from

$\ln \frac{z}{z_{0}}=\frac{u \cdot \kappa}{u_{*}}$

In Eq. (1), $z$ is the measurement height $(m), u$ is the wind speed $\left(\mathrm{m} \mathrm{s}^{-1}\right), \kappa$ is the von Karman constant $(=0.40)$, and $u_{*}$ is the friction velocity $\left(\mathrm{m} \mathrm{s}^{-1}\right)$. 
Evaluation of the atmospheric stability conditions was based on the stability parameter $z / L$, the ratio of the measurement height and the Obukhov length $L$,

$$
L=-\frac{u_{*}^{3}}{\kappa \frac{g}{T} \overline{w^{\prime} T^{\prime}}}
$$

$g$ is the gravitational acceleration $\left(9.81 \mathrm{~m} \mathrm{~s}^{-2}\right), T$ is the sonic temperature $(\mathrm{K})$, and $\overline{w^{\prime} T^{\prime}}$ is the buoyancy flux $\left(\mathrm{K} \mathrm{m} \mathrm{s}^{-1}\right)$ based on the sonic temperature fluctuations.

The net particle flux $F$ can be expressed as

$$
F=\overline{w^{\prime} c^{\prime}}-v_{\mathrm{g}} \bar{c}
$$

where $\overline{w^{\prime} c^{\prime}}$ is the turbulent particle flux $\left(\mathrm{m}^{-2} \mathrm{~s}^{-1}\right), v_{\mathrm{g}}$ is the gravitational settling velocity $\left(\mathrm{m} \mathrm{s}^{-1}\right)$, and $\bar{c}$ is the mean particle concentration $\left(\mathrm{cm}^{-3}\right)$. For particle number fluxes dominated by sub- $50 \mathrm{~nm}$ particles, gravitational settling can be neglected (e.g. Hoppel et al., 2005), and the net particle flux $F$ equals the turbulent particle flux $\overline{w^{\prime} c^{\prime}}$.

Neglecting gravitational settling, the net particle flux $F$ is a combination of particle emission and deposition,

$$
F=\overline{w^{\prime} c^{\prime}}=S_{\text {eff }}-D_{\text {turb }},
$$

where $S_{\text {eff }}$ is an effective surface source strength to account for particle emission, and $D_{\text {turb }}$ describes the turbulent deposition flux.

A normalized flux $v_{t}$, often termed the "deposition velocity" or "transfer velocity", can be obtained by normalizing the turbulent particle flux $\overline{w^{\prime} c^{\prime}}$ with the corresponding particle number concentration $\bar{c}$,

$v_{\mathrm{t}}=-\frac{\overline{w^{\prime} c^{\prime}}}{\bar{c}}$

Normalizing the flux helps to evaluate the relevance of the turbulent flux with respect to the ambient particle number concentration. However, the concept of a transfer velocity according to Eq. (5) is physically unrealistic and contradicts the gradient approach (Foken, 2008). Strictly, the transfer velocity should be defined in terms of the particle number gradient. Then, it can be considered consistent with flux-profile relationships which relate the particle flux and the particle concentration difference between two heights if the effective turbulent exchange between these two heights is known.

The uncertainty of the transfer velocity measurements due to counting statistics, $\Delta v_{\mathrm{t}}$, was approximated according to Fairall (1984) by

$$
\Delta v_{\mathrm{t}}=-\frac{\sigma_{w}}{\sqrt{N}}
$$

with $\mathrm{N}$ : number of counted particles in averaging interval. In $90 \%$ of the observations, the uncertainty due to counting statistics was less than $30 \%$.

Restricted to deposition, $v_{\mathrm{t}}$ can be described as a reciprocal resistance $R_{\mathrm{t}}$ controlling the turbulent flux towards the surface, $v_{\mathrm{t}}=R_{\mathrm{t}}^{-1}$. The total resistance $R_{\mathrm{t}}$ is a combination of the aerodynamic resistance, $R_{\mathrm{a}}$, the quasi-laminar sublayer resistance, $R_{\mathrm{b}}$, and the surface resistance, $R_{\mathrm{c}}$, thus

$v_{\mathrm{t}}=\frac{1}{R_{\mathrm{t}}}=\frac{1}{R_{\mathrm{a}}+R_{\mathrm{b}}+R_{\mathrm{c}}}$

For particle deposition, $\left(R_{\mathrm{b}}+R_{\mathrm{c}}\right)$ is replaced with a combined resistance $R_{\mathrm{S}}$ (Wesely and Hicks, 2000). Applying the resistance analogy, size-resolved particle deposition is calculated using four different parameterizations following the parameterizations presented in Nilsson and Rannik (2001) and Zhang et al. (2001), respectively. The parameterization of $R_{\mathrm{a}}$ and the calculation of $v_{\mathrm{t}}$ using these four different parameterizations can be found in Appendix A. Here, we only repeat the different parameterizations of the combined resistance, $R_{\mathrm{S}}$, which exhibit the most prominent differences:

Nilsson and Rannik (2001) used a parameterization of $R_{\mathrm{S}}$ given by Schack et al. (1985):

$R_{\mathrm{s}, \mathrm{NR}}=\left(A D^{2 / 3}\left(\frac{u_{*}}{z_{0}}\right)^{1 / 2} v^{-1 / 6}+B d_{p}^{2}\left(\frac{u_{*}}{z_{0}}\right)^{3 / 2} v^{-1 / 2}\right)^{-1}$

The terms on the right-hand side account for diffusion and interception, respectively. $D$ is the diffusion coefficient, $v$ is the kinematic viscosity, $d_{\mathrm{p}}$ is the particle diameter, and $A$ and $B$ are empirical parameters depending on the surface type. Nilsson and Rannik (2001) used $A=0.4$ and $B=20$, leading to the best agreement of their measured and calculated transfer velocities. For comparison, we also used the original values $A=0.19$ and $B=18.8$ given by Schack et al. (1985) for water at $u_{*}=0.44 \mathrm{~m} \mathrm{~s}^{-1}$.

A simple parameterization of $R_{\mathrm{S}}$ is given by EMEP (2003) for gas-phase species:

$R_{\mathrm{S}, \mathrm{EMEP}}=\frac{2}{\kappa u_{*}}\left(\frac{v}{0.72 D}\right)^{2 / 3}$

We acknowledge that this parameterization is intended for gas-phase constituents and does not parameterize impaction/interception. However, since the particle number flux is often dominated by sub-50 nm diameter particles which exhibit gas-like behavior (Held et al., 2006), $R_{\mathrm{s}, \mathrm{EMEP}}$ is included for comparison.

Finally, Zhang et al. (2001) use the following parameterization of $R_{\mathrm{S}}$ :

$R_{\mathrm{s}, \mathrm{Zh}}=\left(\varepsilon_{0} u_{*}\left(\left(\frac{v}{D}\right)^{-1 / 2}+\frac{\mathrm{St}^{2}}{400+\mathrm{St}^{2}}\right) \exp \left(-\mathrm{St}^{1 / 2}\right)\right)^{-1}$

Here, the terms on the right-hand side account for diffusion and interception. $\varepsilon_{0}$ is an empirical constant taken as 0.1 , and $\mathrm{St}$ is the Stokes number which is calculated according to Giorgi (1988) as

$\mathrm{St}=\frac{v_{g} u_{*}^{2}}{g v}$ 

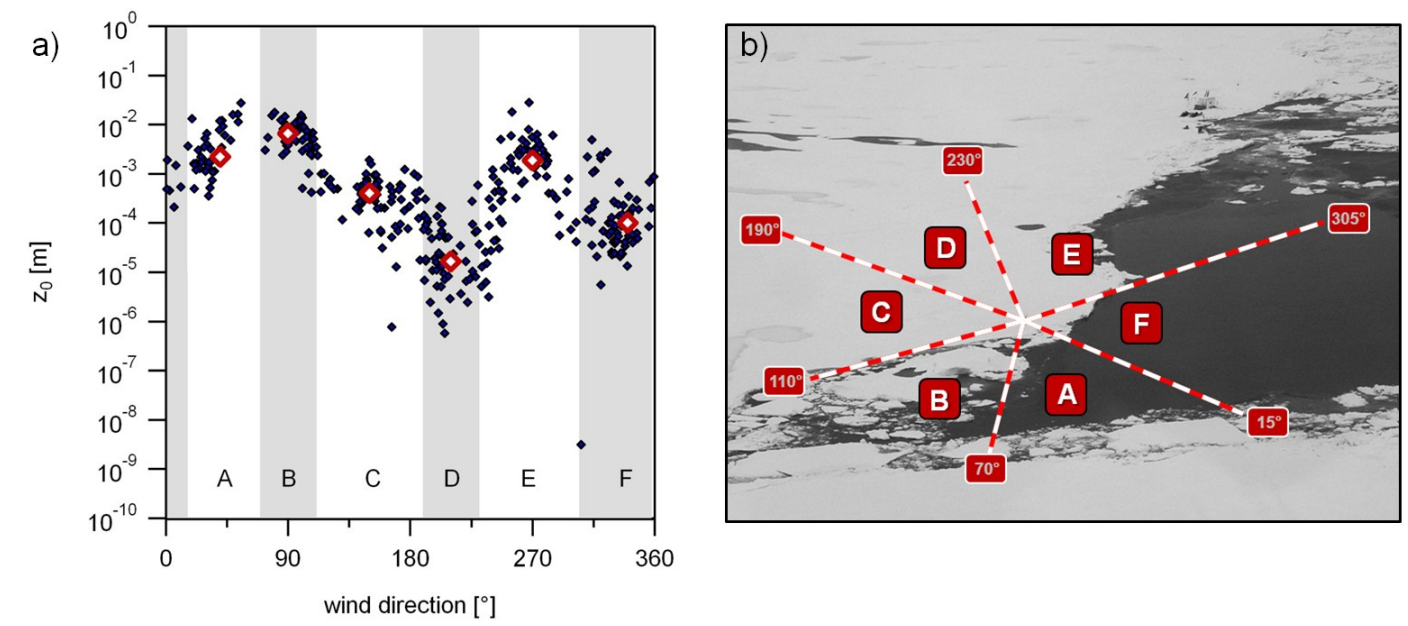

Fig. 2. (a) Roughness length $\mathrm{z}_{0}$ in six wind direction sectors $A-F$; red diamonds represent median $\mathrm{z}_{0}$ values in each wind sector. (b) Aerial view of the measurement site and overlay of the six wind sectors.

\section{Results and discussion}

\subsection{Aerosol flux observations - division into sectors}

Depending on the wind direction, the fetch of the turbulence measurement was from the open lead, the ice floe, pressure ridges, the floe edge, or a combination of these surface features. Based on the surface roughness, expressed through the roughness length $z_{0}$, six sectors were identified with different fetch characteristics.

Figure 2a shows the roughness length $z_{0}$ in six sectors A$\mathrm{F}$, and the corresponding relative wind directions. The wind directions are given relative to the orientation of the sonic anemometer. While the ice floe was rotating with respect to true North, the given relative wind directions are constant in the local frame of reference as shown in Fig. $2 b$.

Figure $2 b$ displays an aerial view of the measurement site and the surface properties of the six sectors. The lowest surface roughness is found in sector D, a smooth ice surface lacking large roughness elements. In contrast, the ice surface in sector $\mathrm{C}$ contains several pressure ridges and large ice blocks. These roughness elements explain somewhat higher $z_{0}$ values in sector $\mathrm{C}$ compared with sector $\mathrm{D}$. The rugged floe edges in sectors B and $\mathrm{E}$ lead to increased surface roughness in these sectors. However, large fractions of smoother ice and lead surfaces contribute to slightly lower $z_{0}$ values in sector E. Sector F provides a wide open lead fetch and exhibits relatively low $z_{0}$ values. In contrast, the open lead fetch in sector A is rather small and the high surface roughness is dominated by the edge of the opposite ice floe. Also, it is important to note that widening and closing of the lead over the measurement period introduces some variability in the contribution of open lead, floe edge and ice surfaces to the measurement fetch from the lead direction.

The roughness length varies mainly between $10^{-2}$ and $10^{-5} \mathrm{~m}$ showing a clear dependence on wind direction due to changes in surface type between sectors. These $z_{0}$ values are in good agreement with typical $z_{0}$ values reported for water and ice surfaces ranging between $10^{-3}$ and $10^{-5} \mathrm{~m}$ (Foken, 2008). Tjernström (2005) estimated a mean value of $z_{0}=3 \times 10^{-3} \mathrm{~m}$ from the Arctic Ocean Experiment 2001, with a similar dependence on wind direction and a span from $10^{-5}$ to $10^{-2} \mathrm{~m}$. Persson et al. (2002) report a mean $z_{0}=$ $4.5 \times 10^{-4} \mathrm{~m}$ based on measurements over snow-covered sea ice from the Surface Heat Budget of the Arctic Ocean (SHEBA) experiment (Uttal et al., 2002) flux tower, while Andreas et al. (2010a) obtain a value of $2.3 \times 10^{-4} \mathrm{~m}$ based on the SHEBA dataset over snow-covered sea ice. Nilsson and Rannik (2001) report median $\mathrm{z}_{0}$ values of $2 \times 10^{-3} \mathrm{~m}$ to $2 \times 10^{-4} \mathrm{~m}$ over smooth ice surfaces in summer and the freeze-up period in the Arctic Ocean. These $z_{0}$ values are very similar to the values observed in this study over snowcovered ice in sector $\mathrm{C}\left(4.0 \times 10^{-4} \mathrm{~m}\right)$ but somewhat higher than sector D.

For the marginal ice zone and summer sea ice with surface characteristics similar to sector B, Andreas et al. (2010b) reported typical drag coefficients that correspond to $z_{0}$ values ranging from $2 \times 10^{-4} \mathrm{~m}$ to $2.5 \times 10^{-3} \mathrm{~m}$, somewhat lower than in sector B $\left(6.6 \times 10^{-3} \mathrm{~m}\right)$. Nilsson and Rannik (2001) found somewhat higher $z_{0}$ over rough ice floes of $2 \times 10^{-2} \mathrm{~m}$.

Over Arctic leads and polynyas, Andreas and Murphy (1986) report a drag coefficient corresponding to $z_{0}$ $=3.2 \times 10^{-4} \mathrm{~m}$. Nilsson and Rannik (2001) give median $\mathrm{z}_{0}$ values of $9 \times 10^{-4} \mathrm{~m}$ and $6 \times 10^{-4} \mathrm{~m}$, which is between our observations in sector A $\left(2.2 \times 10^{-3} \mathrm{~m}\right)$ and sector $\mathrm{F}$ $\left(1.0 \times 10^{-4} \mathrm{~m}\right)$. Clearly, the roughness length in sector A is influenced by the opposite ice floe.

Figure 3 shows the cumulative distribution of the net aerosol number fluxes in the six different sectors. Each trace starts at the lowest measured aerosol flux, and then indicates 


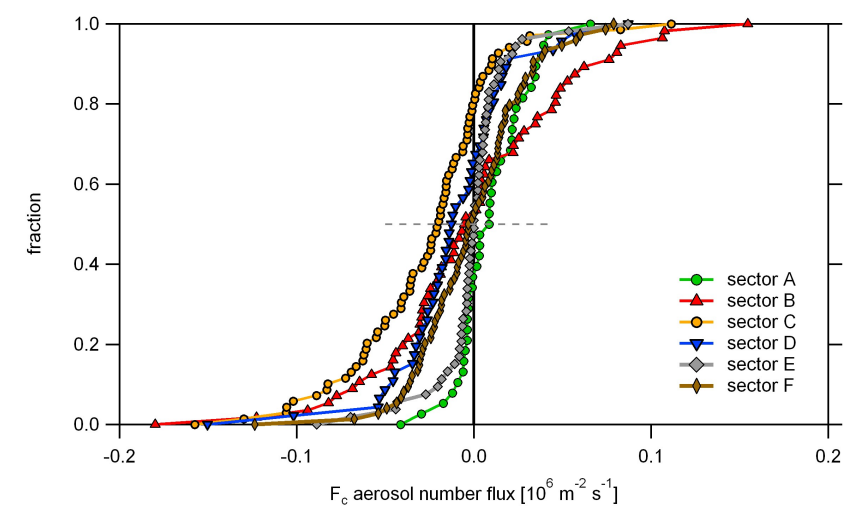

Fig. 3. Cumulative distribution of aerosol number fluxes in six different sectors. Flux value at fraction of 0.5 is the median aerosol number flux.

the fraction of measurements below a certain aerosol number flux in each sector. For example, the value for $F_{\mathrm{c}}=$ $0 \mathrm{~m}^{-2} \mathrm{~s}^{-1}$ indicates the fraction of deposition dominated flux measurements. Clearly, sectors $\mathrm{C}$ and $\mathrm{D}$ exhibit a high fraction of negative (deposition dominated) flux measurements of $80 \%$ and $65 \%$, whereas in sectors B, E and $\mathrm{F}$ more or less equal fractions of positive and negative fluxes were observed. In sector A, more than $60 \%$ of the observed fluxes were dominated by emission. The highest positive (emission dominated) flux measurements were found in sector $\mathrm{B}$, covering rough ice ridges. The rough surface in sector $\mathrm{B}$ also leads to very large deposition dominated flux measurements. Strong deposition dominated flux measurements are also found over the ice floe in sectors $C$ and D. These observations cannot be explained by different particle number concentrations, but are also found in the corresponding transfer velocities summarized in Table 1.

For reference, Table 1 also presents the number of $30 \mathrm{~min}$ periods dominated by deposition $\left(N_{\mathrm{dep}}\right)$ or emission $\left(N_{\mathrm{em}}\right)$, the median values of wind speed and particle number concentration as well as friction velocity $u_{*}$ and roughness length $z_{0}$. The median values of $u_{*}$ and $z_{0}$, wind speed and particle number concentration within each sector are very similar during emission and deposition dominated periods, except for sector A. Here, high particle numbers $\left(147 \mathrm{~cm}^{-3}\right)$ and low wind speeds $\left(1.2 \mathrm{~m} \mathrm{~s}^{-1}\right)$ are observed during an emission dominated period on 18 August, and much lower particle numbers $\left(9 \mathrm{~cm}^{-3}\right)$ yet higher wind speeds $\left(3.1 \mathrm{~m} \mathrm{~s}^{-1}\right)$ during a deposition dominated period on 25 August. The median values of the transfer velocity range from $0.27 \mathrm{~mm} \mathrm{~s}^{-1}$ to $0.68 \mathrm{~mm} \mathrm{~s}^{-1}$ during deposition dominated periods. It is interesting to note that in the current measurements the highest particle number concentrations were found when the measurement is influenced by the open lead, in sectors A and F (Table 1).
The magnitude of the observed deposition velocities, $v_{\mathrm{t}}(\mathrm{dep})$, is in general agreement with earlier estimates of aerosol fluxes over snow and ice surfaces. Again, it should be noted that our aerosol number fluxes are dominated by sub$50 \mathrm{~nm}$ particles. Ibrahim et al. (1983) report aerosol deposition velocities of $v_{\mathrm{t}}=0.39 \mathrm{~mm} \mathrm{~s}^{-1}$ under stable stratification, and $v_{\mathrm{t}}=0.96 \mathrm{~mm} \mathrm{~s}^{-1}$ under unstable conditions using ${ }^{35} \mathrm{~S}$ tagged ammonium sulfate particles $0.7 \mu \mathrm{m}$ in diameter. Bergin et al. (1995) derived aerosol sulfate deposition velocities ranging from $0.23 \mathrm{~mm} \mathrm{~s}^{-1}$ to $0.62 \mathrm{~mm} \mathrm{~s}^{-1}$ at Summit, Greenland, based on particle mass using surrogate surfaces (particle diameter $<15 \mu \mathrm{m}$ ) and impactor data (particle diameter $<10 \mu \mathrm{m}$ ). Duan et al. (1988) observed an average aerosol deposition velocity of particles in the diameter range from 150 to $300 \mathrm{~nm}$ of $v_{\mathrm{t}}=0.34 \mathrm{~mm} \mathrm{~s}^{-1}$ over a partially snow covered field using optical particle counters. Grönlund et al. (2002) report somewhat larger median deposition velocities of $3.3 \mathrm{~mm} \mathrm{~s}^{-1}$ and $8.0 \mathrm{~mm} \mathrm{~s}^{-1}$ dominated by particles with mean diameters of $14 \mathrm{~nm}$ and $42 \mathrm{~nm}$ at two sites over a smooth snow-covered area in Dronning Maud Land, Antarctica. Nilsson and Rannik (2001) measured aerosol number fluxes by eddy covariance with instrumentation similar to our study in a similar setting in the high Arctic. They report median deposition velocities $v_{\mathrm{t}}=0.26 \mathrm{~mm} \mathrm{~s}^{-1}$ over smooth ice surfaces, and $v_{\mathrm{t}}$ ranging from 0.40 to $0.73 \mathrm{~mm} \mathrm{~s}^{-1}$ over open lead surfaces. However, the footprints of their flux measurements were considerably larger than in this study and also possibly include a mixture of open lead and ice surfaces.

In order to compare the aerosol number flux above the open lead and the ice surface, Fig. 4a presents the median aerosol number fluxes in $10^{\circ}$ wind direction bins over the entire measurement period. In addition, the time fraction of emission dominated periods for different relative wind directions is shown in Fig. 4 b. It should be emphasized that a turbulent particle flux value of zero does not imply a lack of particle emission or deposition (cf. Eqs. 3 and 4); it is ambiguous without knowing all other terms of the budget. However, one can easily distinguish two different regimes: for relative wind directions from sectors $\mathrm{A}$ and $\mathrm{F}$, i.e. measurements dominated by the open lead, slightly positive median fluxes indicate aerosol emission, and a high fraction of emission periods can be found. In contrast, for relative wind directions from sectors $\mathrm{C}$ and $\mathrm{D}$, the ice-floe dominated fetch, very few emission dominated periods are observed (Fig. 4b), and the median flux values are mostly negative, indicating net deposition (Fig. 4a). While some of the emission dominated periods are within the range of uncertainties, even a few of the emission dominated periods from the ice floe have to be considered valid emission events. The wind speed is probably too low for resuspension of snow, but resuspension of particles previously deposited and accumulated on the snow surface may be a possible explanation for these events. Sectors $\mathrm{B}$ and $\mathrm{E}$ (grey shading) exhibit a transitional behavior. 
Table 1. Median values of wind speed, particle number concentration, friction velocity $u_{*}$, roughness length $z_{0}$, and transfer velocities $v_{\mathrm{t}}$, respectively, for six wind sectors with different surface characteristics (L: lead, IR: ice ridge, I: ice floe). $N_{\text {dep }}$ is the number of deposition dominated 30 min periods in each sector, $N_{\mathrm{em}}$ of emission dominated periods.

\begin{tabular}{lllllllllll}
\hline Sector & $\begin{array}{l}\text { from } \\
\circ\end{array}$ & $\begin{array}{l}\text { to } \\
\circ\end{array}$ & $\begin{array}{l}N_{\mathrm{dep}} \\
-\end{array}$ & $\begin{array}{l}N_{\mathrm{em}} \\
-\end{array}$ & $\begin{array}{l}\text { Wind } \\
\text { speed } \\
\mathrm{m} \mathrm{s}^{-1}\end{array}$ & $\begin{array}{l}\text { Particle } \\
\mathrm{conc} \\
\mathrm{cm}^{-3}\end{array}$ & $\begin{array}{l}u^{*} \\
\mathrm{~m} \mathrm{~s}^{-1}\end{array}$ & $\begin{array}{l}z_{0} \\
\mathrm{~m}\end{array}$ & $\begin{array}{l}v_{\mathrm{t}}(\mathrm{dep}) \\
\mathrm{mm} \mathrm{s}^{-1}\end{array}$ & Surface \\
\hline $\mathrm{A}$ & 15 & 70 & 15 & 24 & 1.35 & 138 & 0.09 & $2.2 \mathrm{E}-03$ & 0.41 & $\mathrm{~L} / \mathrm{IR}$ \\
$\mathrm{B}$ & 70 & 110 & 30 & 27 & 3.32 & 50 & 0.23 & $6.6 \mathrm{E}-03$ & 0.51 & $\mathrm{IR}$ \\
$\mathrm{C}$ & 110 & 190 & 56 & 14 & 3.82 & 38 & 0.17 & $4.0 \mathrm{E}-04$ & 0.68 & $\mathrm{I}$ \\
$\mathrm{D}$ & 190 & 230 & 31 & 16 & 3.53 & 43 & 0.11 & $1.7 \mathrm{E}-05$ & 0.44 & $\mathrm{I}$ \\
$\mathrm{E}$ & 230 & 305 & 27 & 27 & 2.22 & 12 & 0.12 & $1.9 \mathrm{E}-03$ & 0.56 & $\mathrm{IR} / \mathrm{I} / \mathrm{L}$ \\
$\mathrm{F}$ & 305 & 15 & 39 & 36 & 3.13 & 71 & 0.12 & $1.0 \mathrm{E}-04$ & 0.27 & $\mathrm{~L}$ \\
\hline
\end{tabular}
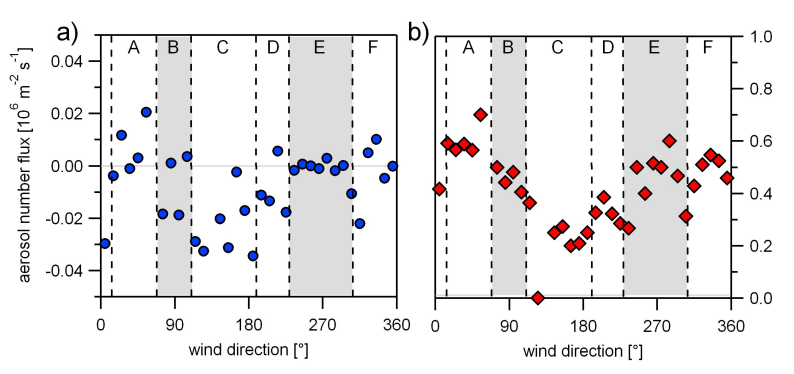

Fig. 4. (a) Median aerosol number fluxes in $10^{\circ}$ wind direction bins. (b) Time fraction of emission episodes averaged over $30^{\circ}$ wind bins and plotted every $10^{\circ}$. Grey shading indicates the transitional wind sectors $\mathrm{B}$ and $\mathrm{E}$.

\subsection{Aerosol flux observations - temporal variability}

In the following, the temporal variability of the measured fluxes will be discussed. Due to the very low flux estimates, a comparison of cumulative fluxes of momentum, buoyancy and particle number concentration is used. This means that emission dominated (positive) fluxes will increase the previously accumulated flux value and deposition dominated (negative) fluxes will decrease it. Thus, a positive slope indicates emission dominated periods, a negative slope indicates deposition dominated periods, and the steeper the slope, the stronger the flux.

Figure 5 shows the wind speed and direction, the stability parameter $z / L$, the particle number concentration, and the cumulative fluxes of momentum, buoyancy, and particle number concentration from 26 to 29 August. During this fourday period, the particle concentration varies between 50 and $100 \mathrm{~cm}^{-3}$ for most of the time. The stability parameter $z / L$ is close to zero in most cases, indicating that stability effects can be neglected. The lead started to freeze over on $27 \mathrm{Au}-$ gust, and it was then continuously covered with a thin layer of ice. In the night from 26 to 27 August emission dominates and there is weak upwards flux of particles, while particle deposition dominates the flux in the afternoon and evening, especially on 28 and 29 August. However, the particle fluxes are very low throughout 27 August even though buoyancy and momentum fluxes exhibit a clear increase in magnitude. On this day, the fetch was mostly over the lead in sector F. However, as noted above, the lead was covered with a thin layer of ice at this time.

The observations discussed above corroborate our findings that the open lead indeed behaved as a source of aerosol particles under certain conditions, yet there is no clear correlation with wind speed or momentum flux. This supports earlier suggestions (e.g. Leck and Bigg, 1999; Leck et al., 2002) that the open lead particle source is not exclusively driven by wind (such as the bubble-bursting mechanism at open sea). This is also consistent with the observations of Scott and Levin (1972) who found open lead particle production without visible bubble activity. They speculated that very small bubbles might still burst at the atmosphere-water interface, and gas might be released from the breakup of microbubbles during melting or freezing processes. Alternative non-wind driven sources of bubbles are the transport of bubbles to the surface by increased turbulence caused by supercooling conditions (Grammatika and Zimmerman, 2001), or bubbles due to respiration of phytoplankton (e.g. Johnson and Wangersky, 1987). Measurements made during the ASCOS campaign confirmed the presence of a population of small $(D<500 \mu \mathrm{m})$ bubbles within the open lead, and an alternative bubble source mechanism driven by the surface heat flux was proposed (Norris et al., 2011).

\subsection{Deposition parameterizations and net flux observations}

The net flux estimates derived from our eddy covariance measurements reflect the combined effect of emission and deposition mechanisms on the turbulent vertical exchange of particles. In order to obtain the emission flux, the deposition must be subtracted from the measured net flux. As noted above, a variety of size-resolved particle deposition parameterizations exist which can be used to estimate the deposition. 

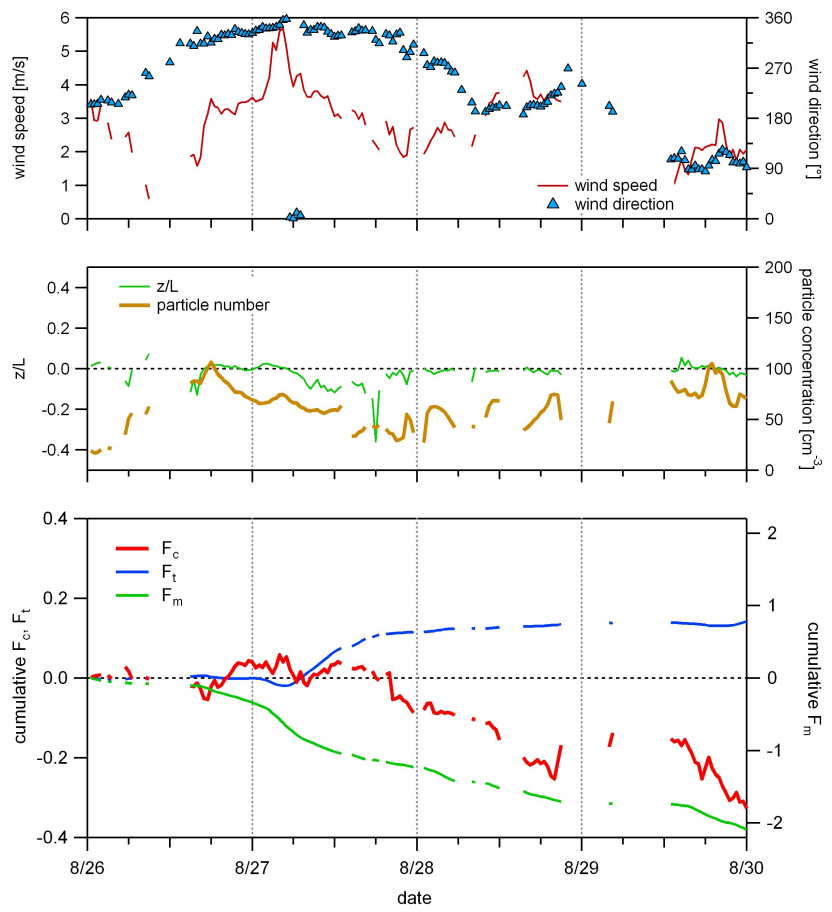

Fig. 5. Top panel shows wind speed (red line) and relative wind direction (triangles) from 26 August through 29 August 2008; middle panel shows stability parameter $z / L$ (green line) and particle number concentration (orange line); bottom panel shows cumulative fluxes of momentum $\left(F_{\mathrm{m}}\right.$, green), buoyancy $\left(F_{\mathrm{t}}\right.$, blue $)$, and particle number $\left(F_{\mathrm{c}}\right.$, red $)$.

However, the uncertainties introduced by the parameterizations add to the measurement uncertainties and require careful consideration before robust conclusions can be drawn.

Figure 6a presents the cumulative particle number flux as measured from 18 to 31 August, and the cumulative deposition fluxes derived from four different particle deposition parameterizations. The large data gap from 21 to 24 August is due to heavy riming on the sonic anemometer, and several smaller data gaps indicate low data quality. When comparing the temporal behavior of the parameterizations, two different pairs of deposition parameterizations can be found. Nilsson and Rannik (2001) use the original parameterization of $R_{\mathrm{S}}$ by Schack et al. (1985), but with different empirical parameters $A$ and $B$ (cf. Eq. 8). Replacing this formulation with a parameterization suggested by EMEP (2003) for gas-phase species yields deposition patterns similar to the parameterization by Zhang et al. (2001), but the absolute values are much smaller.

On 18 August, all parameterizations suggest very low particle deposition indicating that the net flux estimates are close to "true" emission values. On 20 August, the observations are dominated by deposition, which is supported by all parameterizations. Furthermore, the NR (Nilsson and Rannik)
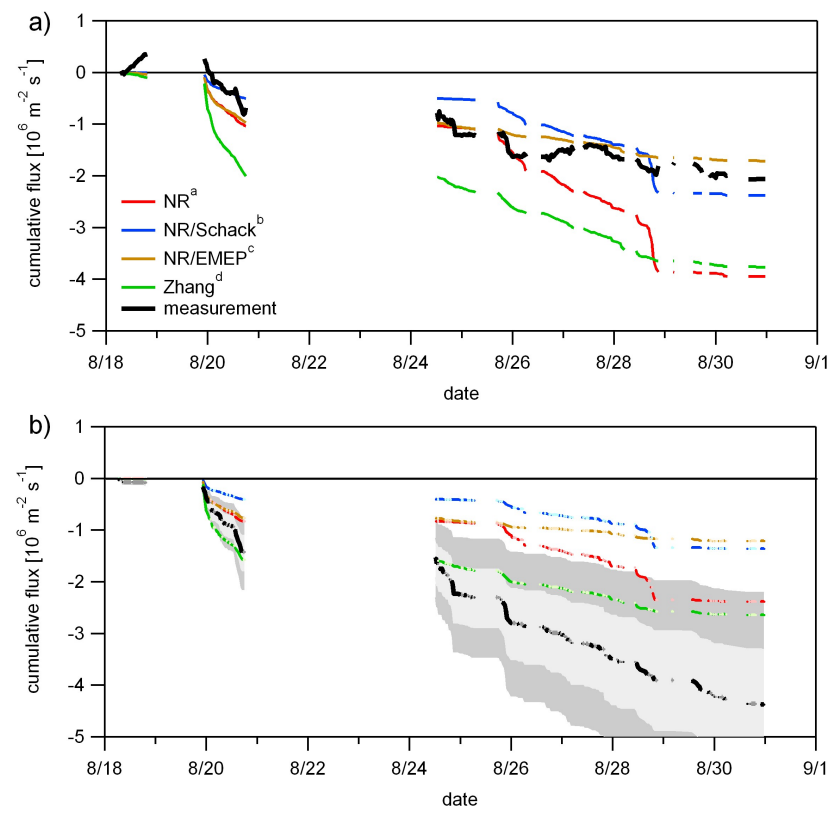

Fig. 6. (a) Measured cumulative particle number flux from 18 to 31 August (black line), and cumulative deposition fluxes derived from four different particle deposition parameterizations according to a Nilsson and Rannik (2001), b Schack et al. (1985), c EMEP (2003), d Zhang et al. (2001). (b) Same as Fig. 6a, but accumulating only during periods when particle deposition was observed. Emission dominated periods are indicated by light colors. Shaded areas represent deviations of $25 \%$ (light grey) and $50 \%$ (dark grey) from the observed deposition flux.

and NR/S (Nilsson and Rannik/Schack) parameterizations show two strong deposition periods during the nights from 25/26 and 28/29 August. The first deposition dominated period on 25/26 August can also be found in the observations, whereas the second period on 28/29 August is qualitatively different from the observed net fluxes. This leads to a strong deviation of the cumulative flux values of the measurement and the NR parameterization at the end of the period considered.

Obviously, none of the deposition parameterizations are intended to reproduce particle emission events. Therefore, in Fig. 6b only deposition dominated periods are taken into account and added to the cumulative flux. When emission dominated positive fluxes are observed, the cumulative flux is not changed and remains at the same value (represented by light colors). The shaded areas indicate deviations of $25 \%$ (light grey) and 50\% (dark grey) from the observed net flux.

On 20 August, the Zhang parameterization is slightly larger than the observed flux, while all other parameterizations are smaller than the observed flux. However, during the period starting on 24 August, all parameterizations tend to yield smaller flux values than observed. Since the parameterizations were not designed specifically for our conditions, we 
are not entirely surprised to find deviations; however, if we postulate some opposing emission fluxes, we would rather expect the models to overestimate in comparison with the observations.

Qualitatively, the Zhang parameterization tracks the observed net flux best. The EMEP parameterization clearly gives flux values much lower than observed. This may be explained by the fact that the EMEP parameterization is originally designed for gas-phase species.

From this evaluation, there is no individual parameterization that can be considered the "best" description of the deposition flux. All parameterizations show periods when they agree with, and periods when they deviate from, the observed fluxes. However, it is not possible to attribute these deviations to measurement uncertainties, or deficiencies of the parameterizations. In general, the EMEP parameterization may be considered a low estimate of particle deposition.

\subsection{Potential contribution of vertical aerosol fluxes to the airborne particle burden}

In order to evaluate the significance of direct particle emission and deposition, and its potential contribution to the atmospheric aerosol burden, the change in particle concentration due to turbulent particle emission and deposition fluxes will be considered. The goal is to obtain a rough estimate of the order of magnitude of the aerosol flux contribution to changes in particle number concentrations. For these calculations, the measured net fluxes were used to include both emission and deposition processes.

In this simplified thought experiment we consider a closed box. The top boundary is given by the height up to which effective mixing occurs. We neglect horizontal advection because we want to examine the local effect of vertical particle transport by turbulence only. We also neglect processes such as new particle formation and chemical reactions that potentially affect the particle number concentration. Thus, particles enter and leave the box through aerosol emission and deposition at the surface/atmosphere boundary only. We evaluate the changes of particle number concentration over a time interval of $30 \mathrm{~min}$, i.e. the averaging interval of the eddy covariance calculations. At this time resolution, turbulent mixing will reduce concentration differences with height.

It should be noted that a uniform particle distribution with height implies lack of a particle gradient and thus, no net turbulent particle flux would occur. Nevertheless, as a firstorder approximation, we assume that at the end of each time interval particles emitted into or removed from the atmosphere will be distributed uniformly in a well-mixed volume defined by the emission/deposition area and the effective mixing height $h_{\text {eff }}(m)$ (a truly well-mixed layer, not the full boundary layer depth). Thus, for any emission/deposition flux $F_{\mathrm{c}}$ in units $\mathrm{m}^{-2} \mathrm{~s}^{-1}$, an estimate of the area fraction of open leads $a_{\mathrm{OL}}$, and a given $h_{\text {eff }}(m)$, we can derive a change
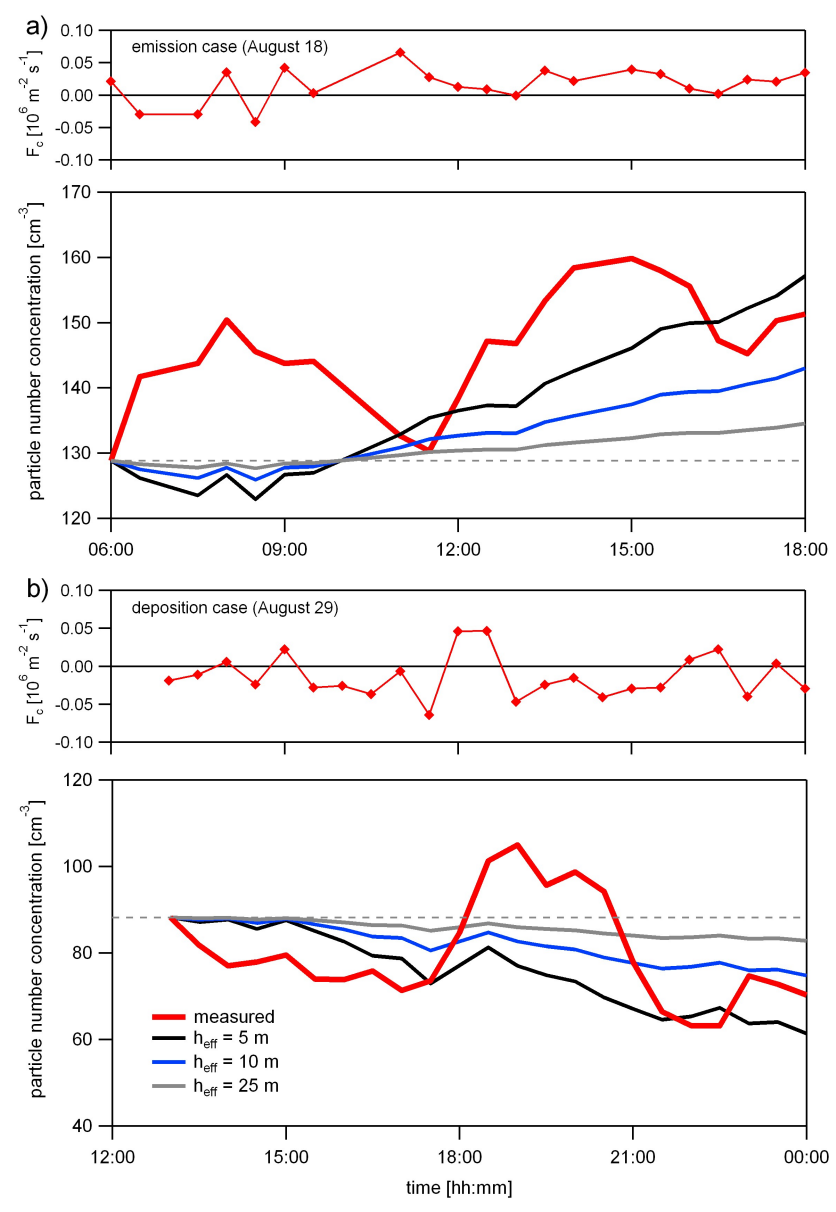

Fig. 7. Temporal change of the particle number concentration as measured and theoretically expected due to the measured turbulent aerosol flux $F_{\mathrm{c}}$, assuming three different scenarios of effective mixing heights $h_{\text {eff }}$, and a $25 \%$ area fraction of the open leads. (a) Emission dominated case on 18 August, and (b) deposition dominated case on 29 August.

in particle concentration due to the measured turbulent flux $F_{\mathrm{c}}$ from the open leads, $\Delta_{h_{\mathrm{eff}}}=F_{\mathrm{c}} \times \mathrm{a}_{\mathrm{OL}} / h_{\mathrm{eff}}$, and compare it with the measured change of particle concentration, $\Delta c$.

In Fig. 7, we compare the measured temporal change of the particle number concentration with the change as expected due to the turbulent particle fluxes assuming three different effective mixing heights and a given area fraction of the open leads. We assume that $25 \%$ of the surface area is covered by open leads (which can be considered a high estimate), and $75 \%$ is ice-covered. The mixing height is $h_{\text {eff }}=5 \mathrm{~m}$ in scenario $1, h_{\text {eff }}=10 \mathrm{~m}$ in scenario 2 , and $h_{\text {eff }}=25 \mathrm{~m}$ in scenario 3. This assumption is a clear oversimplification of the seaice-environment and does not take into account any temporal and spatial evolution of the sea-ice-distribution.

The emission case in Fig. 7a shows much stronger variability in the measured particle number concentration than can be explained by the measured particle fluxes alone. In this example, the best estimate of the effective mixing 
Table 2. Percentiles of changes in particle number concentration as expected from measured aerosol number fluxes assuming $h_{\mathrm{eff}}=25 \mathrm{~m}$ and a $25 \%$ area fraction of open leads (expected), and as observed from direct particle number measurements (observed), during emission dominated periods, during deposition dominated periods, and for the entire measuring period.

\begin{tabular}{lccccccc}
\hline & \multicolumn{3}{c}{ expected } & & \multicolumn{3}{c}{ observed } \\
\cline { 2 - 3 } \cline { 6 - 7 } $\begin{array}{l}\text { percentile } \\
\%\end{array}$ & $\begin{array}{c}\text { emission } \\
\left(\mathrm{cm}^{-3} \mathrm{~h}^{-1}\right)\end{array}$ & $\begin{array}{c}\text { deposition } \\
\left(\mathrm{cm}^{-3} \mathrm{~h}^{-1}\right)\end{array}$ & $\begin{array}{c}\text { total } \\
\left(\mathrm{cm}^{-3} \mathrm{~h}^{-1}\right)\end{array}$ & & $\begin{array}{c}\text { emission } \\
\left(\mathrm{cm}^{-3} \mathrm{~h}^{-1}\right)\end{array}$ & $\begin{array}{c}\text { deposition } \\
\left(\mathrm{cm}^{-3} \mathrm{~h}^{-1}\right)\end{array}$ & $\begin{array}{c}\text { total } \\
\left(\mathrm{cm}^{-3} \mathrm{~h}^{-1}\right)\end{array}$ \\
\hline 5 & 0.1 & -3.7 & -2.8 & & 0.4 & -35.2 & -24.5 \\
10 & 0.1 & -2.5 & -2.0 & & 0.7 & -24.1 & -16.7 \\
50 & 0.6 & -0.8 & -0.2 & & 6.6 & -5.3 & -0.3 \\
90 & 2.5 & -0.1 & 1.3 & & 24.2 & -0.6 & 15.5 \\
95 & 3.0 & -0.1 & 2.1 & & 34.7 & -0.3 & 23.2 \\
\hline
\end{tabular}

height as determined by visual inspection of tethersonde profiles considering potential temperature, relative humidity and wind speed is $h_{\mathrm{eff}}=25 \mathrm{~m}$ (scenario 3 ). This scenario results in changes of the particle number concentration of $5-6 \mathrm{~cm}^{-3}$ over a time period of $12 \mathrm{~h}$. A change in particle number comparable to the observed changes after $12 \mathrm{~h}$ is only produced assuming much shallower effective mixing heights of scenarios 1 and 2 , but even then, the short-term variability cannot be explained by $\Delta_{h_{\text {eff }}}$.

The same general results are found in the deposition case shown in Fig. 7b, where the best estimate of the effective mixing height is $10 \mathrm{~m}$ (scenario 2). While the observed drop of the particle concentration from about 90 to $70 \mathrm{~cm}^{-3}$ over a period of $11 \mathrm{~h}$ is similar to the concentration change in scenario 2 , the short-term variability found in the measured particle number concentration cannot be reproduced by any reasonable scenario of $\Delta_{h_{\text {eff }}}$.

Overall, the evaluation of the aerosol flux contribution to changes in particle number concentrations can only be considered a rough estimate of the order of magnitude of this factor. In particular, the mixed layer depths represent absolute minimum depths over which concentration changes should be evaluated; turbulent mixing will extend above these levels but become increasingly weak.

Nevertheless, we find the direct impact of the turbulent particle flux on the atmospheric particle concentration to be minor. In about $85 \%$ of the evaluated cases, the flux-derived particle concentration change $\Delta_{25}$ (i.e. assuming a typical effective mixing height of $25 \mathrm{~m}$, and a $25 \%$ area fraction of open leads) is less than $1 \mathrm{~cm}^{-3} \mathrm{~h}^{-1}$, whereas more than $75 \%$ of the observed particle concentration changes $\Delta_{\mathrm{c}}$ are greater than $1 \mathrm{~cm}^{-3} \mathrm{~h}^{-1}$.

Table 2 shows characteristic values of the particle concentration change $\Delta_{25}$ as expected from the measured aerosol number flux, and the observed particle concentration change $\Delta_{\mathrm{c}}$ during emission dominated periods, during deposition dominated periods, and for the entire measuring period. Note that the $5 \%$ percentile, for example, gives the weakest $5 \%$ of $\Delta_{25}$ for the emission dominated periods but the strongest $5 \%$ of $\Delta_{25}$ for the deposition dominated periods due to opposing signs of the flux values. While the shape of the cumulative frequency distributions of $\Delta_{25}$ and $\Delta_{c}$ are similar, the absolute magnitude of the particle concentration change differs by a factor of about 10 . Therefore, additional processes such as horizontal transport, new particle formation, and chemical transformations must strongly affect the particle number concentration.

\section{Conclusions}

We have successfully carried out direct eddy covariance measurements of particle number fluxes on an ice floe in the central Arctic Ocean and found episodic aerosol emission from open leads. Simultaneous and independent gradient measurements of particle concentrations - which will be presented elsewhere - corroborate our finding that open leads can indeed act as particle sources in the Arctic Ocean. Overall, the direct contribution of the open lead particle emissions to the atmospheric aerosol number concentration appears to be of minor importance, and can only explain a few percent of the observed particle number variability. Additional processes such as advection, chemical transformation and degradation, or vertical mixing from aloft in the upper layers of the marine boundary layer seem at a first approximation to have a significant impact on atmospheric particle numbers in the central Arctic (Bigg et al., 1996, 2001; Leck and Persson, 1996). Unfortunately, no information about the size of the emitted particles is available from our direct flux measurements. Thus, it remains unclear if open leads are a significant source of aerosol mass to the Arctic boundary layer.

Moreover, we are only beginning to understand what happens to the emitted particles in the atmosphere. It has been proposed that aerosol particles emitted from open leads in the Arctic are enriched in organic compounds from the marine surface microlayer (e.g. Leck and Bigg, 2005a; Bigg and Leck, 2008; Matrai et al., 2008). These gel-like substances found in the aerosol were postulated to have properties 
consistent with algal and bacterial exopolymer secretions or marine microgels (Decho, 1990). According to Verdugo et al. (2004), the marine microgels span the whole size spectrum from colloidal-size nanogels containing single macromolecules entangled to form single-chain networks to micrometer-size gels (loose matrix associated with the aggregates or granular structures) that can aggregate to tight capsules reaching several $100 \mu \mathrm{m}$ in diameter.

The assembly and dispersion of macromolecules can be affected by environmental parameters, such as UV-B radiation (280-320 nm) dispersing or inhibiting microgel formation, and/or $\mathrm{pH}$ and temperature inducing microgel volume phase changes (Orellana and Verdugo, 2003; Chin et al., 1998). Thus, one can speculate that degradation and break-up is a potential atmospheric fate of the open lead-derived aerosol. As suggested by Leck and Bigg (2010) this can lead to a large number of smaller daughter particles derived from a small number of large parent particles emitted from the open lead.

Finally, the melting of sea ice in a changing climate will further increase the fraction of open leads in the Arctic pack ice, and potentially increase the relevance of the open lead particle source. It is very likely that these particles will then play a role as cloud condensation nuclei, and thus provide a direct feedback to the regional Arctic climate.

\section{Appendix A}

In all particle deposition parameterizations, the aerodynamic resistance $R_{\mathrm{a}}$ is expressed according to Seinfeld and Pandis (1998) as

$R_{\mathrm{a}}= \begin{cases}\frac{1}{k u_{*}}\left(\ln \left(\frac{z}{z_{0}}\right)+4.7\left(\frac{z}{L}-\frac{z_{0}}{L}\right)\right) & \frac{z}{L}>0 \\ \frac{1}{k u_{*}} \ln \left(\frac{z}{z_{0}}\right) & \frac{z}{L}=0 \\ \frac{1}{k u_{*}}\left(\ln \left(\frac{z}{z_{0}}\right)+\ln \left(\frac{\left(\eta_{0}^{2}+1\right)\left(\eta_{0}+1\right)^{2}}{\left(\eta^{2}+1\right)(\eta+1)^{2}}\right)+2\left(\tan ^{-1} \eta-\tan ^{-1} \eta_{0}\right)\right) & \frac{z}{L}<0\end{cases}$

Here, $k$ is the von Karman constant, $u_{*}$ is the friction velocity, $z$ is the measurement height, $z_{0}$ is the roughness length, $L$ is the Obukhov length (cf. Eq. 2), $\eta=(1-$ $15 z / L)^{0.25}$, and $\eta_{0}=\left(1-15 z_{0} / L\right)^{0.25}$.

Nilsson and Rannik (2001) calculate the transfer velocity $v_{\mathrm{t}}$ as

$v_{\mathrm{t}}=v_{\mathrm{g}}+\frac{1}{R_{\mathrm{a}}+R_{\mathrm{s}}+R_{\mathrm{a}} R_{\mathrm{s}} v_{\mathrm{g}}}$

where $v_{\mathrm{g}}$ is the gravitational settling velocity, and $R_{\mathrm{S}}$ is the combined surface resistance as given in Eq. (8). Equation A2 is also used with the parameterization by Nilsson and Rannik (2001) using the original values $A=0.19$ and $B=18.8$ given by Schack et al. (1985), and with the simple parameterization of $R_{\mathrm{S}}$ by EMEP (2003) for gas-phase species given in Eq. (9).
In contrast, Zhang et al. (2001) calculate the transfer velocity $v_{\mathrm{t}}$ as

$v_{\mathrm{t}}=v_{\mathrm{g}}+\frac{1}{R_{\mathrm{a}}+R_{\mathrm{s}}}$,

where $R_{\mathrm{S}}$ is the combined surface resistance as given in Eq. (10).

Acknowledgements. This work is part of ASCOS (the Arctic Summer Cloud Ocean Study). We are grateful to Otto Klemm, Westfälische Wilhelms-Universität Münster, Germany, and Margaret Yelland, National Oceanography Centre, Southampton, UK, for providing instrumentation for the eddy covariance setup. AH was supported by the Bert Bolin Center for Climate Research at Stockholm University. ASCOS was made possible by funding from the Knut and Alice Wallenberg Foundation, the Swedish Research Council and the DAMOCLES European Union 6th Framework Integrated Research Project. The Swedish Polar Research Secretariat (SPRS) provided access to the icebreaker Oden and logistical support. We are grateful to the Swedish Polar Research Secretariat logistics staff and to Oden's captain Mattias Peterson and his crew. ASCOS is an IPY project under the AICI-IPY umbrella and is an endorsed SOLAS project.

Edited by: G. de Leeuw

\section{References}

Andreas, E. L. and Murphy, B.: Bulk transfer coefficients for heat and momentum over leads and polynyas, J. Phys. Oceanogr., 16, 1875-1883, 1986.

Andreas, E. L., Persson, P. O. G., Grachev, A. A., Jordan, R. E., Horst, T. W., Guest, P. S., and Fairall, C. W.: Parameterizing turbulent exchange over sea ice in winter, J. Hydrometeorol., 11, 87-104, 2010a.

Andreas, E. L., Horst, T. W., Grachev, A. A., Persson, P. O. G., Fairall, C. W., Guest, P. S., and Jordan, R. E.: Parametrizing turbulent exchange over summer sea ice and the marginal ice zone, Quart. J. Roy. Meteor. Soc, 136, 927-943, 2010b.

Bergin, M. H., Jaffrezo, J.-L., Davidson, C. I., Dibb, J. E., Pandis, S. N., Hillamo, R., Maenhaut, W., Kuhns, H. D., and Makela, T.: The contributions of snow, fog, and dry deposition to the summer flux of anions and cations at Summit, Greenland, J. Geophys. Res., 100, 16275-16288, 1995.

Bigg, E. K.: Ice forming nuclei in the high Arctic, Tellus, 48B, 322-328, 1996.

Bigg, E. K. and Leck, C.: Cloud-active particles over the central Arctic Ocean, J. Geophys. Res., 106, 32155-32166, 2001.

Bigg, E. K. and Leck, C.: The composition of fragments of bubbles bursting at the ocean surface, J. Geophys. Res., 113, D11209, doi:10.1029/2007JD009078, 2008.

Bigg, E. K., Leck, C., and Nilsson, E. D.: Sudden changes in arctic atmospheric aerosol concentrations during summer and autumn, Tellus, 48B, 254-271, 1996.

Bigg, E. K., Leck, C., and Nilsson, E. D.: Sudden changes in aerosol and gas concentrations in the central Arctic marine boundary layer - causes and consequences, J. Geophys. Res., 106, 32167$32185,2001$. 
Bigg,, E. K, Leck, C., and Tranvik, L.: Particulates of the surface microlayer of open water in the central Arctic Ocean in summer, Mar. Chem., 91, 131-141, 2004.

Carrio, G. G., Jiang, H., and Cotton, W. R.: Impact of aerosol intrusions on Arctic boundary layer clouds. Part I: 4 May 1998 case, J. Atmos. Sci., 62, 3082-3093, 2005.

Chin, W.-C, Orellana, M. V., and Verdugo, P.: Spontaneous assembly of marine dissolved organic matter into polymer gels, Nature, 39, 568-572, 1998.

Covert, D. S., Wiedensohler, A., Aalto, P., Heintzenberg, J., McMurry, P. H., and Leck, C.: Aerosol number size distributions from 3 to $500 \mathrm{~nm}$ diameter in the arctic marine boundary layer during summer and autumn, Tellus B, 48, 197-212, 1996.

Decho, A. W.: Microbial exopolymer secretions in ocean environments: their role(s) in food webs and marine processes, Oceanogr. Mar. Biol. Ann. Rev., 28, 73-153, 1990.

Duan, B., Fairall, C. W., and Thomson, D. W.: Eddy correlation measurements of the dry deposition of particles in wintertime, J. Appl. Meteorol., 27, 642-652, 1988.

EMEP: Transboundary acification, eutrophication and ground level ozone in Europe, Part I: Unified EMEP model description, Status Report 1/2003, 2003.

Fairall, C. W.: Interpretation of eddy-correlation measurements of particulate deposition and aerosol flux, Atmos. Environ., 18, 1329-1337, 1984.

Feingold, G., Cotton, W. R., Kreidenweis, S. M., and Davis, J. T.: The impact of giant cloud condensation nuclei on drizzle formation in stratocumulus: Implications for cloud radiative properties, J. Atmos. Sci., 56, 4100-4117, 1999.

Foken, T.: Micrometeorology, Springer, Berlin, 306 pp., 2008.

Foken, T. and Wichura, B.: Tools for quality assessment of surfacebased flux measurements, Agr. Forest Meteorol., 78, 83-105, 1996.

Giorgi, F.: Dry deposition velocities of atmospheric aerosols as inferred by applying a particle dry deposition parameterization to a general circulation model, Tellus, 40B, 23-41, 1988.

Grammatika, M. and Zimmerman, W. B.: Microhydrodynamics of flotation processes in the sea surface layer, Dynam. Atmos. Oceans, 34, 327-348, 2001.

Grönlund, A., Nilsson, D., Koponen, I. K., Virkkula, A., and Hansson, M.: Aerosol dry deposition measured with eddy-covariance technique at Wasa and Aboa, Dronning Maud Land, Antarctica, Ann. Glaciol., 35A, 355-361, 2002.

Heintzenberg, J. and Leck, C.: Seasonal variation of the atmospheric aerosol near the top of the marine boundary layer over Spitzbergen related to the Arctic sulphur cycle, Tellus, 46B, 5267, 1994.

Held, A., Nowak, A., Wiedensohler, A., and Klemm, O.: Field measurements and size-resolved model simulations of turbulent particle transport to a forest canopy, J. Aerosol Sci., 37, 786-798, 2006.

Hoppel, W. A., Caffrey, P. F., and Frick, G. M.: Particle deposition on water: Surface source versus upwind source, J. Geophys. Res., 110, D10206, doi:10.1029/2004JD005148, 2005.

Horst, T. W.: A simple formula for attenuation of eddy fluxes measured with first-order-response scalar sensors, Bound. Lay. Meteorol., 82, 219-233, 1997.

Ibrahim, M., Barrie, L. A., and Fanaki, F.: An experimental and theoretical investigation of the dry deposition of particles to snow, pine trees and artificial collectors, Atmos. Environ., 17, 781-788, 1983.

Intrieri, J. M., Fairall, C. W., Shupe, M. D., Persson, P. O. G., Andreas, E. L., Guest, P. S., and Moritz, R. E.: An annual cycle of Arctic surface cloud forcing at SHEBA, J. Geophys. Res., 107, 8039, doi:10.1029/2000JC000439, 2002.

Johnson, B. D. and Wangersky, P. J.: Microbubbles: Stabilization by monolayers of adsorbed particles, J. Geophys. Res., 92, 14641-14647, 1987.

Karlsson, J. and Svensson, G.: The simulation of Arctic clouds and their influence on the winter surface temperature in present-day climate in the CMIP3 multi-model dataset, Clim. Dyn., 36, 623635, 2011.

Leck, C. and Bigg, E. K.: Aerosol production over remote marine areas - a new route, Geophys. Res. Lett., 26, 3577-3580, 1999.

Leck, C. and Bigg, E. K.: Biogenic particles in the surface microlayer and overlaying atmosphere in the central Arctic Ocean during summer, Tellus, 57B, 305-316, 2005a.

Leck, C. and Bigg, E. K.: Evolution of the marine aerosol - A new perspective, Geophys., Res., Lett., 32, L19803, doi:10.1029/2005GL023651, 2005 b.

Leck, C. and Bigg, E. K.: New particle formation of marine biological origin, Aerosol Sci. Technol., 44, 570-577, 2010.

Leck, C. and Persson, C.: Seasonal and short-term variability in dimethyl sulfide, sulfur dioxide and biogenic sulfur and sea salt aerosol particles in the arctic marine boundary layer, during summer and autumn, Tellus, 48B, 272-299, 1996.

Leck, C., Norman, M., Bigg, E. K., and Hillamo, R.: Chemical composition and sources of the high Arctic aerosol relevant for fog and cloud formation, J. Geophys. Res., 107(D12), 4135, doi:10.1029/2001JD001463, 2002.

Leck, C., Tjernström, M., Matrai, P., Swietlicki, E., and Bigg, K.: Can marine micro-organisms influence melting of the Arctic pack ice?, Eos Trans., 85, 25-36, 2004.

Lenton, T. M., Held, H., Kriegler, E., Hall, J. W., Lucht, W., Rahmstorf, S., and Schellnhuber, H. J.: Tipping elements in the Earths climate system, P. Natl. Acad. Sci., 105, 1786-1793, doi:10.1073/pnas.0705414105, 2008.

Lohmann, U. and Leck, C.: Importance of submicron surface-active organic aerosols for pristine Arctic clouds, Tellus, 57B, 261-268, 2005.

Matrai, P. A., Tranvik, L., Leck, C., and Knulst, J. C.: Are high Arctic surface microlayer a potential source of aerosol organic precursors?, Mar. Chem., 108, 109-122, 2008.

Möhler, O., DeMott, P. J., Vali, G., and Levin, Z.: Microbiology and atmospheric processes: the role of biological particles in cloud physics, Biogeosciences, 4, 1059-1071, doi:10.5194/bg-4-10592007, 2007.

Nilsson, E. D. and Rannik, Ü.: Turbulent aerosol fluxes over the Arctic Ocean: 1. Dry deposition over sea and pack ice, J. Geophys. Res., 106, 32125-32137, 2001.

Norris, S. J., Brooks, I. M., de Leeuw, G., Sirevaag, A., Leck, C., Brooks, B. J., Birch, C. E., and Tjernström, M.: Measurements of bubble size spectra within leads in the Arctic summer pack ice, Ocean Sci., 7, 129-139, doi:10.5194/os-7-129-2011, 2011.

Orellana, M. V. and Verdugo, P.: Ultraviolet radiation blocks the organic carbon exchange between the dissolved phase and the gel phase in the ocean, Limnol. Oceanogr., 48, 1618-1623, 2003.

Persson, P. O. G., Fairall, C. W., Andreas, E. L., Guest, P. 
S., and Perovich, D. K.: Measurements near the Atmospheric Surface Flux Group tower at SHEBA: Near-surface conditions and surface energy budget, J. Geophys. Res., 107(C10), 8045, doi:10.1029/2000JC000705, 2002.

Prenni, A. J., Harrington, J. Y., Tjernström, M., DeMott, P. J., Avramov, A., Long, C. N., Kreidenweis, S. M., Olsson, P. Q., and Verlinde, J.: Can ice-nucleating aerosols affect Arctic seasonal climate?, B. Am. Meteorol. Soc., 88, 541-550, 2007.

Rasmussen, R. M., Geresdi, I., Thompson, G., Manning, K., and Karplus, E.: Freezing drizzle formation in stably stratified layer clouds: The role of radiative cooling of cloud droplets, cloud condensation nuclei, and ice initiation, J. Atmos. Sci., 59, 837860, 2002.

Schack, C. J., Pratsinis, S. E., and Friedlander, S. K.: A general correlation for deposition of suspended particles from turbulent gases to completely rough surfaces, Atmos. Environ., 19, 953960, 1985.

Scott, W. D. and Levin, Z.: Open channels in sea ice (leads) as ion sources, Science, 177, 425-426, 1972.

Seinfeld, J. H. and Pandis, S. N.: Atmospheric chemistry and physics: From air pollution to climate change, New York, Wiley, 1326 pp., 1998.

Thomas, C. and Foken, T.: Re-evaluation of integral turbulence characteristics and their parameterisations, in: Proceedings of the 15th Conference on Turbulence and Boundary Layers, Wageningen, NL, 15-19 July 2002, American Meteorological Society, 129-132, 2002.

Tjernström, M.: The summer Arctic boundary layer during the Arctic Ocean Experiment 2001 (AOE-2001), Bound. Lay. Meteorol., 117, 5-36, 2005.

Tjernström, M., Sedlar, J., and Shupe, M.: How well do regional climate models reproduce radiation and clouds in the Arctic? An evaluation of ARCMIP simulations, J. Appl. Meteorol. Clim., 47, 2405-2422, 2008.
Twomey, S.: Pollution and the planetary albedo, Atmos. Environ., 8, 1251-1265, 1974.

Uttal, T. J., Curry, J. A., McPhee, M. G., Perovich, D. K., Moritz, R. E., Maslanik, J. A., Guest, P. S., Stern, H. L., Moore, J. A., Turenne, R., Heiberg, A., Serreze, M. C., Wylie, D. P., Persson, O. G., Paulson, C. A., Halle, C., Morison, J. H., Wheeler, P. A., Makshtas, A., Welch, H., Shupe, M. D., Intrieri, J. M., Stamnes, K., Lindsey, R. W., Pinkel, R., Pegau, W. S., Stanton, T. P., and Grenfeld, T. C.: Surface Heat Budget of the Arctic Ocean, Bull. Am. Meteorol. Soc., 83, 255-276, 2002.

Verdugo, P., Alldredge, A. L., Azam, F., Kirchman, D. L, Passow, U., and Santschi, P. A.: The oceanic gel phase: a bridge in the DOM-POM continuum, Mar. Chem., 92, 67-85, 2004.

Walsh, J. E., Kattsov, W. M., Chapman, W. L., Govorkova, V., and Pavlova, T.: Comparison of Arctic climate by uncoupled and coupled global models, J. Climate, 15, 1429-1446, 2002.

Webb, E. K., Pearman, G. I., and Leuning, R.: Correction of flux measurements for density effects due to heat and water vapour transfer, Quart. J. Roy. Meteor. Soc., 106, 85-100, 1980.

Wells, M. L. and Goldberg, E. D.: Occurrence of small colloids in sea water, Nature, 353, 342-344, 1991.

Wesely, M. L. and Hicks, B. B.: A review of the current status of knowledge on dry deposition, Atmos. Environ., 34, 2261-2282, 2000.

Wilczak, J. M., Oncley, S. P., and Stage, S. A.: Sonic anemometer tilt correction algorithms, Bound. Lay. Meteorol., 99, 127-150, 2001.

Zhang, L., Gong, S., Padro, J., and Barrie, L.: A size-segregated particle dry deposition scheme for an atmospheric aerosol module, Atmos. Environ., 35, 549-560, 2001. 